Research Paper

\title{
Nab-paclitaxel plus S-1 in advanced pancreatic adenocarcinoma (NPSPAC): a single arm, single center, phase II trial
}

\author{
Yan Shi ${ }^{1}$, Sui Zhang ${ }^{2}$, Quanli Han ${ }^{1}$, Jie Li $^{3}$, Huan Yan ${ }^{1}$, Yao Lv ${ }^{1}$, Huaiyin Shi ${ }^{3}$, Rong \\ Liư ${ }^{4}$ and Guanghai Dai ${ }^{1}$ \\ ${ }^{1}$ Medical Oncology Department 2, Chinese PLA General Hospital and Chinese PLA Medical School, Beijing, P.R. China \\ ${ }^{2}$ Department of Medical Oncology, Dana-Farber Cancer Institute and Harvard Medical School, Boston, MA, USA \\ ${ }^{3}$ Pathology Department, Chinese PLA General Hospital and Chinese PLA Medical School, Beijing, P.R. China \\ ${ }^{4}$ Department of Hepatobiliary and Pancreatic Surgical Oncology, Chinese PLA General Hospital and Chinese PLA Medical \\ School, Beijing, P.R. China \\ Correspondence to: Guanghai Dai, email: daigh301@vip.sina.com \\ Keywords: nab-paclitaxel, S-1, objective response rate, survival, advanced pancreatic adenocarcinoma \\ Received: April 28, $2017 \quad$ Accepted: August 28, $2017 \quad$ Published: September 28, 2017 \\ Copyright: Shi et al. This is an open-access article distributed under the terms of the Creative Commons Attribution License 3.0 (CC \\ BY 3.0), which permits unrestricted use, distribution, and reproduction in any medium, provided the original author and source are \\ credited.
}

\section{ABSTRACT}

This single-arm, phase II trial is to investigate efficacy and safety of nab-paclitaxel plus S-1 as first-line treatment in advanced pancreatic cancer. Nab-paclitaxel was administered at $120 \mathrm{mg} / \mathrm{m}^{2}$ intravenously on day 1 and $8, \mathrm{~s}-1$ was given twice a day orally on day 1-14 of each 21-day cycle, for 6 cycles. The primary endpoint was objective response rate (ORR), the secondary endpoints were progression-free survival (PFS), overall survival (OS) and safety. The ORR in intent-to-treat population $(\mathrm{N}=60)$ by either blinded independent review (BIR) or investigator assessment was $\mathbf{5 0 . 0 \%}$. Median PFS (mPFS) by BIR and median OS (mOS) were 5.6 months (95\%CI, 4.6 to $6.6 \mathrm{~m})$ and 9.4 months $(95 \% \mathrm{CI}, 8.0$ to $10.8 \mathrm{~m})$, respectively. The most common grade 3 or 4 toxicities were leukopenia/neutropenia (35\%) and fatigue ( $8.3 \%)$. Subgroup analyses based on BIR showed a remarkable ORR ( $>70 \%)$ was achieved in patients with female gender, $\geq 50 \%$ decline from baseline CA19-9, and developed grade 3 or 4 leukopenia/neutropenia. Remarkable survival benefit was statistically significant in female (mPFS: $7.7 \mathrm{~m}$, mOS: $18.2 \mathrm{~m}$ ), $\geq 50 \%$ decline from baseline CA19-9 (mPFS: $6.8 \mathrm{~m}$, mOS: $11.8 \mathrm{~m}$ ), objective responders (mPFS: $6.9 \mathrm{~m}$, mOS: $12.2 \mathrm{~m}$ ), and ECOG of 0 at baseline (mPFS: 7.5m, mOS: $16.1 \mathrm{~m}$ ). Nab-paclitaxel plus S-1 showed encouraging ORR and manageable toxicities, which is an effective alternative treatment regimen for advanced pancreatic cancer. (https://clinicaltrials.gov/ number, NCT02124317)

\section{INTRODUCTION}

Pancreatic adenocarcinoma (PAC) is the seventh leading cause of cancer-related death worldwide [1]. In 2015 , the estimated new cases and associated deaths of PAC were 90,100 and 79,400, respectively, in China [2]. The majority of PAC patients have unresectable advanced disease (locally advanced or metastatic) and lack of effective therapeutic options at the time of diagnosis [3], which leave patients miserable life expectancy with a 5 -year survival rate less than $5 \%[4,5]$. Gemcitabine monotherapy was the only approved first-line treatment in patients with advanced PAC for about 15 years before 2011, however the objective response rate (ORR) was $4-9 \%$, whereas the median overall survival (OS) was 5.47 months, and 1-year survival rate was $17-23 \%[6-9]$.

Recent two large, randomized phase III studies showed promising effects in metastatic PAC treated by FOLFIRINOX (5-FU, leucovorin, irinotecan, and oxaliplatin) or nab-paclitaxel plus gemcitabine $[8,10]$. However, the confirmed ORRs of these two regimens were 23-34\%, which still unmet clinical expectation, in addition 
there were significantly increased hematologic adverse events of grade 3 or higher. S-1 is an oral fluoropyrimidine derivative, which demonstrated effectiveness and good tolerability in gastric and some other cancers. In GEST and JASPAC01 studies, S-1 monotherapy demonstrated comparable or even superior clinical benefit in treatment of advanced and postoperative PAC compared to gemcitabine $[11,12]$. Meanwhile S-1 had less adverse events, especially in neutropenia compared to gemcitabine ( $\geq$ grade $3: 8.8 \%$ vs. $41 \%$ in GEST; $13 \%$ vs. $72 \%$ in JASPAC 01$)$. Therefore, S-1 is theoretically a favorable alternative partner for nabpaclitaxel given its non-inferior antitumor activity and better tolerability compared to gemcitabine in treatment of PAC. This phase II study was designed to investigate the efficacy and safety of nab-paclitaxel in combination with S-1 as the first-line treatment in patients with locally advanced and metastatic PAC.

\section{RESULTS}

\section{Patient characteristics}

Between April 2014 and October 2016, a total of 60 patients were enrolled. Fifty-five patients (91.7\%) had metastatic disease and 5 patients had locally advanced PAC. Thirty-one patients $(51.7 \%)$ had an Eastern Cooperative Oncology Group (ECOG) performance status of 0 , and all patients received at least 2 cycles of nabpaclitaxel in combination with S-1. Three patients had history of prior surgical resection including one treated with gemcitabine alone as adjuvant therapy more than six months before enrollment, and the other two did not receive adjuvant therapy due to hypoproteinemia and patient's personal decision. Baseline characteristics of patients are shown in Table 1.

\section{Efficacy}

Five patients had no response evaluation including 4 lost follow-up and 1 worsening ECOG performance status after 2 cycles of treatment. The ORR in intentionto-treat (ITT) population ( $\mathrm{N}=60)$ based on investigator's assessment was 50\% (2 complete response [CR], 3.3\%; and 28 partial response [PR] 46.7\%) (Table 2), and the disease control rate (DCR) was $81.7 \%$. The ORR and DCR by blinded independent review (BIR) were 50\% (1 CR, 1.7\%; and 29 PR, 48.3\%) and 71.7\%, respectively. A water fall plot of the best response based on independent imaging assessment of nab-paclitaxel plus S-1 treatment is shown in Figure 1A, whereas the best response was defined as the best target lesion(s) response recorded from the start to the end of the treatment. In the 55 evaluable patient population, the ORR and DCR were $54.5 \%, 89.1 \%$ and $54.5 \%, 78.2 \%$ by investigator and BIR, respectively.

In 52 patients with elevated carbohydrate antigen 19-9 (CA19-9) at baseline, 32 (59.6\%) had $\geq 50 \%$ decline from baseline CA19-9. The association between maximum percentage change in CA19-9 levels of the patients and the confirmed best overall response according to the BIR is displayed on a waterfall plot (Figure 1B).

\section{Treatment exposure and safety}

The median treatment cycle was 4 (range, 2 to 6 cycles, total 275 cycles). Eleven patients (18.3\%) required dose reduction of one or both drugs due to adverse events, among which 7 patients had reduction in the nab-paclitaxel dose and 8 patients had reduction in the S-1 dose. The median relative dose intensities of nabpaclitaxel and S-1 were both $100 \%$. Twenty-seven patients $(45 \%)$ completed 6 cycles of planned treatment, while 33 patients discontinued treatment due to disease progression $(\mathrm{N}=15)$, patients' refusal $(\mathrm{N}=11)$, lost follow-up $(\mathrm{N}=4)$ and adverse event $(\mathrm{N}=3)$. Total 23 patients received $\mathrm{S}-1$ maintenance treatment, whereas 16 patients were after 6 cycles, while the other 5 and 2 patients had treatment response but started maintenance treatment after 4 and 5 cycles due to patients' desire or adverse event.

The frequencies of common hematological and nonhematological adverse events (noted by $\geq 10 \%$ of patients) are listed in Table 3 . The most commonly reported adverse events including all grades were leukopenia/neutropenia $(88.3 \%)$, sensory neuropathy $(78.3 \%)$, nausea/vomiting $(71.7 \%)$ and anemia (70.0\%). In total, $18(30 \%)$ and 7 (11.7\%) patients experienced 'at least once' grade 3 or grade 4 (leukopenia or neutropenia only) adverse events respectively, whereas 17 grade 3 and 5 grade 4 were successfully resolved after supportive management. The most common grade 3 or 4 treatment related toxicities were leukopenia/neutropenia (35\%), fatigue $(8.3 \%)$, anemia $(6.7 \%)$ and sensory neuropathy $(5 \%)$. Of the 3 patients discontinued treatment due to unresolvable adverse events, 2 experienced grade 4 neutropenia and grade 3 mucositis, and the treatment had to be terminated after 4 cycles due to decreasing ECOG performance score after treatment delay and dose reduction. Another had grade 3 neutropenia and fatigue, similarly the treatment had to be terminated due to worsening fatigue after dose reduction before cycle 3 . One patient died within 30 days after the last treatment due to disease progression rather than treatment-related toxicities (Table 3).

\section{Second-line therapy}

Second-line therapy was administered in 18 patients $(30 \%)$ in our cohort. The regimens were gemcitabine alone in 7 patients and gemcitabine-based combination in 11 patients.

\section{Survival analysis}

By March 1, 2017, 45 patients died and 4 patients lost follow-up. Median progression-free survival (mPFS) 
Table 1: Patient demographics and disease characteristics at baseline

\begin{tabular}{|c|c|c|}
\hline Characteristic & No. & $\%$ \\
\hline \multicolumn{3}{|l|}{ Age, years } \\
\hline Median (Range) & $56(34-74)$ & \\
\hline \multicolumn{3}{|l|}{ Sex } \\
\hline Male & 42 & 70.0 \\
\hline Female & 18 & 30.0 \\
\hline \multicolumn{3}{|l|}{ ECOG performance status } \\
\hline 0 & 31 & 51.7 \\
\hline 1 & 29 & 48.3 \\
\hline \multicolumn{3}{|l|}{ Diabetes } \\
\hline Yes & 12 & 20.0 \\
\hline No & 48 & 80.0 \\
\hline \multicolumn{3}{|c|}{ Tumor grade differentiation } \\
\hline Well/Moderate & 43 & 71.7 \\
\hline Moderate-poor/Poor & 17 & 28.3 \\
\hline \multicolumn{3}{|l|}{ Stage } \\
\hline Locally advanced & 5 & 8.3 \\
\hline Metastatic & 55 & 91.7 \\
\hline \multicolumn{3}{|l|}{ Location of primary tumor } \\
\hline Head/neck of pancreas & 17 & 28.3 \\
\hline Body/tail of pancreas & 43 & 71.7 \\
\hline Prior surgical resection * & 3 & 5.0 \\
\hline \multicolumn{3}{|l|}{ Site of metastatic disease } \\
\hline Abdomen/peritoneal & 9 & 15.0 \\
\hline Liver & 47 & 78.3 \\
\hline Lung & 8 & 13.3 \\
\hline Others & 3 & 5.0 \\
\hline Liver only & 24 & 40.0 \\
\hline \multicolumn{3}{|l|}{ No. of metastatic disease } \\
\hline 0 & 5 & 8.3 \\
\hline 1 & 30 & 50.0 \\
\hline 2 & 15 & 25.0 \\
\hline$\geq 3$ & 10 & 16.7 \\
\hline \multicolumn{3}{|c|}{ CA19-9 baseline levels, No. } \\
\hline Normal & 8 & 13.3 \\
\hline Elevated & 52 & 86.7 \\
\hline \multicolumn{3}{|l|}{ CA19-9 baseline, $\mathrm{U} / \mathrm{mL}^{\#}$} \\
\hline Median (Range) & $2189(1->20,000)$ & \\
\hline
\end{tabular}

Abbreviation: ECOG, Eastern Cooperative Oncology Group.

* Three patients had history of prior surgical resection including one treated with gemcitabine alone as adjuvant therapy more than six months before enrollment.

\# Normal CA19-9 levels are $\leq 35 \mathrm{U} / \mathrm{mL}$ in our hospital. 
Table 2: Response rates per RECIST 1.1 criteria in patients treated with nab-paclitaxel plus S-1 (ITT population)

\begin{tabular}{lcc}
\hline Tumor response, No. $(\%)$ & Best response by investigator review & Best response by independent review \\
\hline Complete response $^{\#}$ & $2(3.3)$ & $1(1.7)$ \\
Partial response $^{\#}$ & $28(46.7)$ & $29(48.3)$ \\
Stable disease & $19(31.7)$ & $13(21.7)$ \\
Progressive disease & $6(10.0)$ & $12(20.0)$ \\
Not assessable* & $5(8.3)$ & $5(8.3)$ \\
Objective response rate & $30(50.0)$ & $30(50.0)$ \\
Disease control rate & $49(81.7)$ & $43(71.7)$ \\
\hline
\end{tabular}

Abbreviation: ITT, Intention-to-Treat.

\# Complete response and partial response were all confirmed at least 4 weeks apart according to RECIST 1.1 criteria.

* Five patients had no response evaluation due to lost follow-up after 2 cycles of treatment in 4 patients and one had worsening Eastern Cooperative Oncology Group performance status.

Table 3: Treatment-related adverse events occurring in $\geq 10 \%$ of patients in ITT population $(\mathrm{N}=60)$

\begin{tabular}{|c|c|c|c|c|c|c|c|c|c|c|}
\hline \multirow[t]{2}{*}{ Adverse event } & \multicolumn{2}{|c|}{ Grade 1} & \multicolumn{2}{|c|}{ Grade 2} & \multicolumn{2}{|c|}{ Grade 3} & \multicolumn{2}{|c|}{ Grade 4} & \multicolumn{2}{|c|}{ Total } \\
\hline & No. & $\%$ & No. & $\%$ & No. & $\%$ & No. & $\%$ & No. & $\%$ \\
\hline \multicolumn{11}{|l|}{ Hematologic } \\
\hline Anemia & 19 & 31.7 & 19 & 31.7 & 4 & 6.7 & 0 & 0 & 42 & 70.0 \\
\hline $\begin{array}{l}\text { Leukopenia/ } \\
\text { Neutropenia }\end{array}$ & 14 & 23.3 & 18 & 30.0 & 14 & 23.3 & 7 & 11.7 & 53 & 88.3 \\
\hline Thrombocytopenia & 13 & 21.7 & 3 & 5.0 & 0 & 0 & 0 & 0 & 16 & 26.7 \\
\hline \multicolumn{11}{|l|}{ Nonhematologic } \\
\hline Fatigue & 8 & 13.3 & 4 & 6.7 & 5 & 8.3 & 0 & 0 & 17 & 28.3 \\
\hline Diarrhea & 3 & 5.0 & 2 & 3.3 & 1 & 1.7 & 0 & 0 & 6 & 10.0 \\
\hline AST/ALT elevated & 12 & 20.0 & 3 & 5.0 & 0 & 0 & 0 & 0 & 15 & 25.0 \\
\hline Nausea/ Vomiting & 35 & 58.3 & 6 & 10.0 & 2 & 3.3 & 0 & 0 & 43 & 71.7 \\
\hline Hand-foot syndrome & 9 & 15.0 & 4 & 6.7 & 0 & 0 & 0 & 0 & 13 & 21.7 \\
\hline Mucositis & 6 & 10.0 & 1 & 1.7 & 2 & 3.3 & 0 & 0 & 9 & 15.0 \\
\hline Sensory neuropathy & 22 & 36.7 & 22 & 36.7 & 3 & 5.0 & 0 & 0 & 47 & 78.3 \\
\hline
\end{tabular}

Abbreviation: ITT, Intention-to-Treat; AST, Aspartate transaminase; ALT, Alanine transaminase.

according to the investigator assessment and BIR were 5.8 months (95\% CI, 4.9 to $6.7 \mathrm{~m})$ and 5.6 months $(95 \%$ CI, 4.6 to $6.6 \mathrm{~m})$, respectively. Median OS (mOS) time for the study cohort was 9.4 months (95\% CI, 8.0 to $10.8 \mathrm{~m})$ (Figure 2).

\section{Subgroup analysis}

We further stratified analyses on the subgroups to distinguish the population potentially received more benefit from nab-paclitaxel in combination with S-1. Female $(76 \%)$, patients with $\geq 50 \%$ decline from baseline CA19-9 (77\%), and those had grade 3 or 4 leukopenia or neutropenia (75\%) gained better ORR based on BIR (Table 4).

In terms of subgroup survival analyses, median PFS by BIR and median OS in female were 7.7 and 18.2 months compared to 5.0 months $(\mathrm{P}=0.002)$ and 8.5 months $(\mathrm{P}=0.002)$ in male, respectively. The patients with baseline ECOG performance score of 0 had longer mPFS and mOS than those of 1 (mPFS $7.5 \mathrm{~m}$ vs $5 \mathrm{~m}, \mathrm{P}=0.005$; $\mathrm{mOS} 16.1 \mathrm{~m}$ vs $7.6 \mathrm{~m}, \mathrm{P}=0.01$ ). As expected, the favorable responders (PR or CR) was associated with better PFS and OS compared to non-responders (SD+PD) assessed by BIR (mPFS $6.9 \mathrm{~m}$ vs $3.3 \mathrm{~m}, \mathrm{P}=0.002$; mOS: $12.2 \mathrm{~m}$ vs $5.7 \mathrm{~m}, \mathrm{P}<0.001)$. Similarly, the patients with $\geq 50 \%$ decline from baseline CA19-9 also 
Table 4: Subgroup analyses of objective response rates by blinded independent review and investigator review

\begin{tabular}{|c|c|c|c|c|c|}
\hline Characteristic & No. $(\%)$ & $\begin{array}{l}\text { ORR by independent } \\
\text { review }(95 \% \mathrm{CI})\end{array}$ & $\mathbf{P}$ & $\begin{array}{l}\text { ORR by investigator } \\
\text { review }(95 \% \mathrm{CI})\end{array}$ & $\mathbf{P}$ \\
\hline Age & & & 0.35 & & 0.49 \\
\hline$\leq 56$ & $30(50.0)$ & $48 \%(31 \%-66 \%)$ & & $59 \%(41 \%-75 \%)$ & \\
\hline$>56$ & $30(50.0)$ & $61 \%(42 \%-76 \%)$ & & $50 \%(33 \%-67 \%)$ & \\
\hline Sex & & & 0.03 & & 0.03 \\
\hline Male & $42(70.0)$ & $45 \%(30 \%-60 \%)$ & & $45 \%(30 \%-60 \%)$ & \\
\hline Female & $18(30.0)$ & $76 \%(53 \%-90 \%)$ & & $76 \%(53 \%-90 \%)$ & \\
\hline ECOG performance status & & & 0.49 & & 0.69 \\
\hline 0 & $31(51.7)$ & $50 \%(33 \%-67 \%)$ & & $57 \%(39 \%-73 \%)$ & \\
\hline 1 & $29(48.3)$ & $59 \%(41 \%-75 \%)$ & & $52 \%(34 \%-69 \%)$ & \\
\hline Diabetes & & & 0.50 & & 0.50 \\
\hline Yes & $12(20.0)$ & $64 \%(35 \%-85 \%)$ & & $45 \%(21 \%-72 \%)$ & \\
\hline No & $48(80.0)$ & $52 \%(38 \%-66 \%)$ & & $57 \%(42 \%-70 \%)$ & \\
\hline Tumor grade differentiation & & & 0.27 & & 0.62 \\
\hline Well/Moderate & $43(71.7)$ & $50 \%(35 \%-65 \%)$ & & $53 \%(37 \%-67 \%)$ & \\
\hline Moderate-poor/Poor & $17(28.3)$ & $67 \%(42 \%-85 \%)$ & & $60 \%(36 \%-80 \%)$ & \\
\hline Stage & & & 0.49 & & 0.49 \\
\hline Locally advanced & $5(8.3)$ & $40 \%(12 \%-77 \%)$ & & $40 \%(12 \%-77 \%)$ & \\
\hline Metastatic & 55 (91.7) & $56 \%(42 \%-69 \%)$ & & $56 \%(42 \%-69 \%)$ & \\
\hline Location of primary tumor & & & 0.05 & & 0.18 \\
\hline Head of pancreas & $17(28.3)$ & $33 \%(15 \%-58 \%)$ & & $40 \%(20 \%-64 \%)$ & \\
\hline Body or tail of pancreas & $43(71.7)$ & $63 \%(47 \%-76 \%)$ & & $60 \%(45 \%-74 \%)$ & \\
\hline CA19-9 baseline levels & & & 0.78 & & 0.29 \\
\hline Normal & $8(13.3)$ & $50 \%(22 \%-78 \%)$ & & $38 \%(14 \%-69 \%)$ & \\
\hline Elevated & $52(86.7)$ & $55 \%(41 \%-69 \%)$ & & $57 \%(43 \%-70 \%)$ & \\
\hline$\geq 50 \%$ decline from baseline CA $19-9^{*}$ & & & $<0.001$ & & 0.003 \\
\hline Yes & $32(61.5)$ & $77 \%(59 \%-88 \%)$ & & $73 \%(56 \%-86 \%)$ & \\
\hline No & $20(38.5)$ & $18 \%(6 \%-41 \%)$ & & $29 \%(13 \%-53 \%)$ & \\
\hline Leukopenia/Neutropenia $^{\#}$ & & & 0.02 & & 0.02 \\
\hline Grade $0-2$ & $39(65.0)$ & $43 \%(28 \%-59 \%)$ & & $43 \%(28 \%-59 \%)$ & \\
\hline$\geq$ Grade 3 & $21(35.0)$ & $75 \%(53 \%-89 \%)$ & & $75 \%(53 \%-89 \%)$ & \\
\hline
\end{tabular}

Abbreviation: ECOG, Eastern Cooperative Oncology Group; ORR, objective response rate.

* The change of CA19-9 after treatment was evaluated in 52 patients with elevated CA19-9 baseline levels.

* Grade of leukopenia/Neutropenia was assessed according to the National Cancer Institute Common Terminology Criteria for Adverse

Events (version 4.0).

had longer PFS (6.8m vs $3.7 \mathrm{~m}, \mathrm{P}=0.02)$ and $\mathrm{OS}(11.8 \mathrm{~m}$ vs $5.7 \mathrm{~m}, \mathrm{P}=0.02$ ) compared to the rest.

\section{DISCUSSION}

The treatment response of nab-paclitaxel and S-1 in this phase II trial met and exceeded our expectation in patients with advanced PAC. The remarkable ORR of 50\% in ITT population, supported by BIR, was far exceeded our hypothesis of achieving $20 \%$, and better than the historic data (ORR less than 35\%) in the previous studies with cytotoxic regimens in advanced or metastatic PAC [8-11]. With respect to the secondary endpoints (safety, PFS and OS), this twoagent combination also showed good tolerability with a median PFS of 5.6 months by BIR and a median OS of 9.4 months, which was comparable to other combinations of two-cytotoxic-drug regimens, such as nab-paclitaxel with gemcitabine and gemcitabine with S-1 [10-12]. 
Although this was a single arm trial, the outstanding ORR suggested it is worth for investigators to put more attention on this treatment combination, and further investigation should be conducted in PAC. Recently, some studies revealed synergistic activity of the combination of nab-paclitaxel and S-1 in PAC from bench to bedside, which provided sufficient scientific base of our study. Suenaga M. et al. reported that S-1 and nab-paclitaxel had a synergistic effect in vitro and showed greater efficacy than monotherapy in vivo [13]. The possible mechanism of this combination may be due to the improvement of the stromal composition (stromal depletion) and tumor angiogenesis in the subcutaneous model. Li JA. et al. further proved the efficacy of this combination in patientderived pancreatic cancer xenograft (PDX) mouse models [14]. They found that S-1 and nab-paclitaxel showed
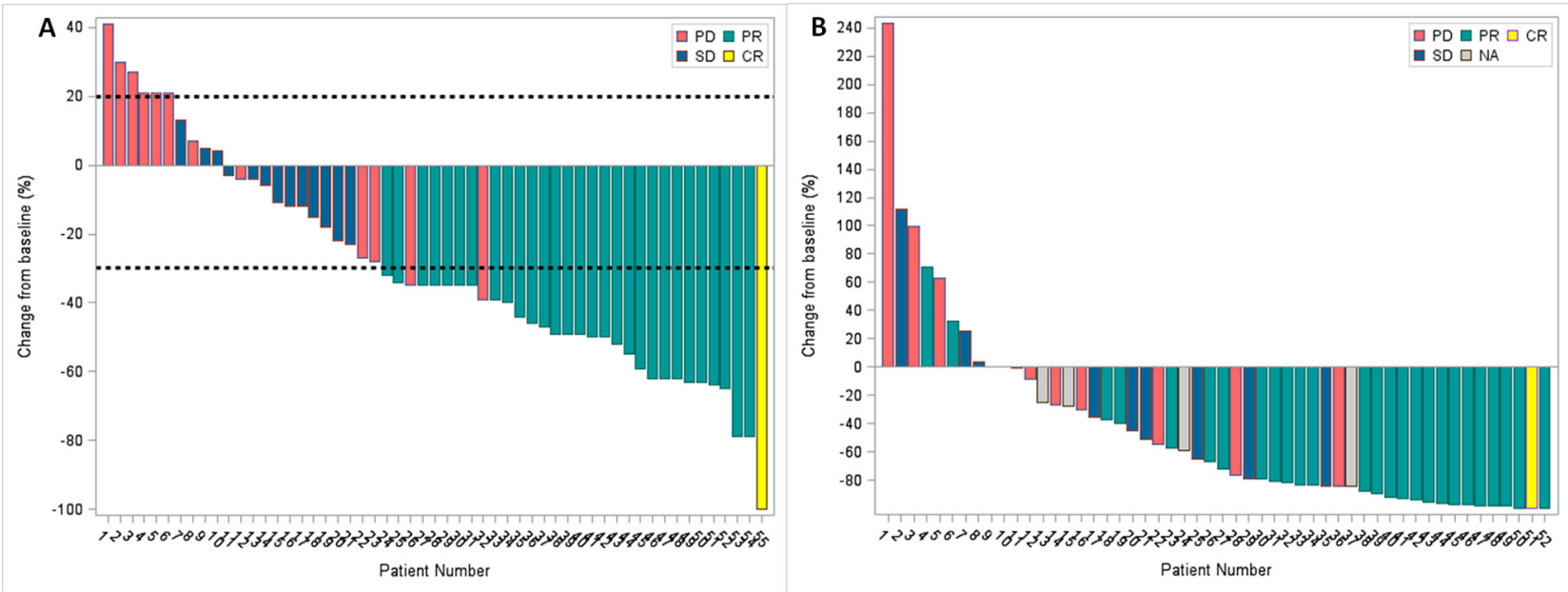

Figure 1: Waterfall plots, the color keys indicate the best overall response by blinded independent review. (A) the best percentage change in target lesion determined by RECIST 1.1 for all evaluable patients $(\mathrm{N}=55)$, and the dashed lines at $20 \%$ and $-30 \%$ represent the progressive disease and partial response, respectively; (B) the best percentage change of CA19-9 in evaluable patients who had an elevated CA19-9 at baseline ( $\mathrm{N}=52)$. Abbreviation: $\mathrm{CR}$, completed response; PR, partial response; SD, stable disease; PD, progressive disease; NA, not available.

A

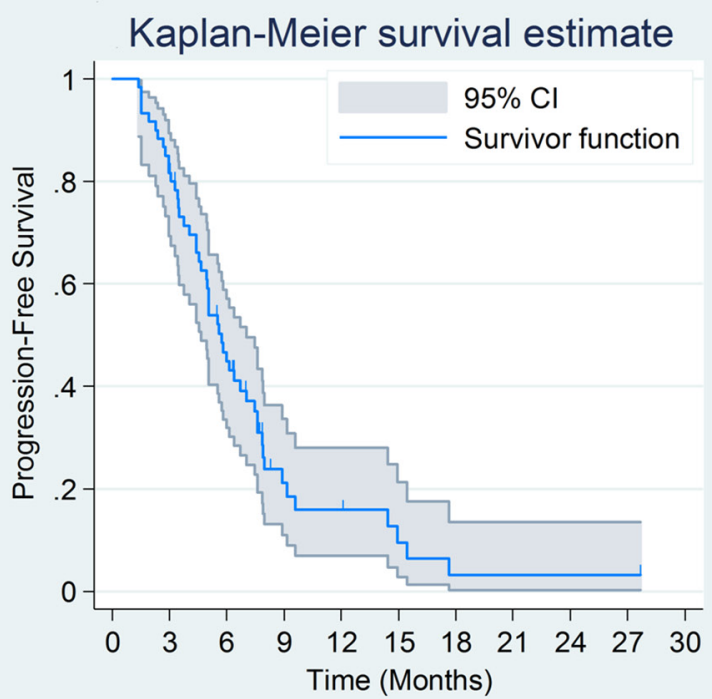

No. at risk

$\begin{array}{lllllllllll}60 & 48 & 25 & 8 & 6 & 3 & 1 & 1 & 1 & 1 & 0\end{array}$
B

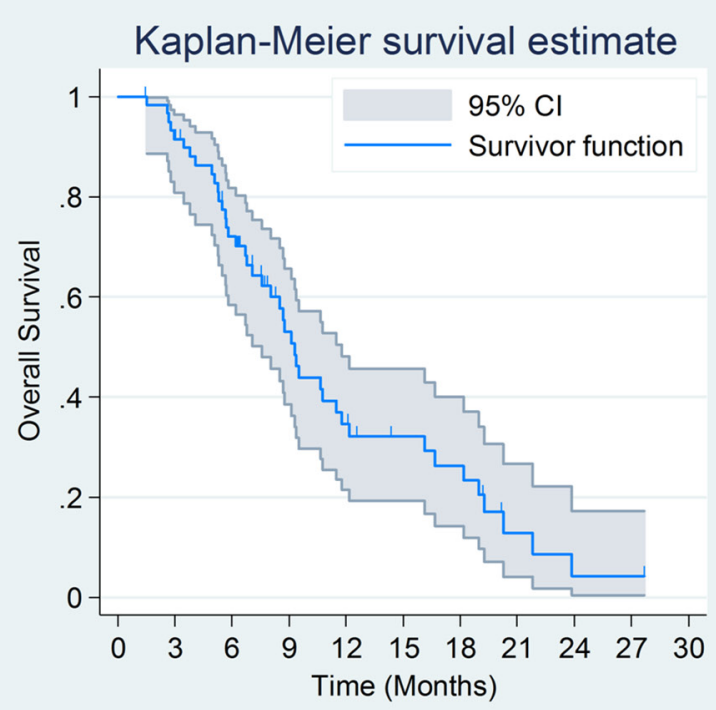

No. at risk

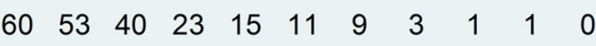

Figure 2: Progression-free survival (A) by blinded independent review and overall survival curves (B) of 60 patients with advanced pancreatic cancer treated with nab-paclitaxel plus S-1. 
significantly better antitumor activity than monotherapy, and this combination played a role in stroma depletion and increasing vascularization in PDX models. In fact, the efficacy and safety of the same treatment combination was established in the advanced breast cancer and gastric cancer $[15,16]$. Furthermore, the combination of nabpaclitaxel with simplified leucovorin and fluorouracil showed good tolerability and efficacy (over 50\% patients were progression-free at 4 months) as first-line chemotherapy for patients with metastatic pancreatic cancer in a recent phase II trial [17]. Given these preclinical and preliminary clinical data, the combination of nab-paclitaxel and S-1 could theoretically be an option for pancreatic cancer.

Our subgroup analyses showed the remarkable ORR $(>70 \%)$ was achieved in patients with female gender, $\geq$ $50 \%$ decline from baseline CA19-9, and developed grade 3 or 4 leukopenia or neutropenia. Remarkable survival benefit was statistically significant in female (mPFS: $7.7 \mathrm{~m}$, mOS: $18.2 \mathrm{~m}$ ), $\geq 50 \%$ decline from baseline CA19-9 (mPFS: 6.8m, mOS: 11.8m), Response Evaluation Criteria in Solid Tumor (RECIST) responders (mPFS: 6.9m, mOS: $12.2 \mathrm{~m}$ ), and ECOG of 0 at baseline (mPFS: $7.5 \mathrm{~m}$, mOS: $16.1 \mathrm{~m}$ ). Early in 1998, Micheli A. et al. reported female patients typically survive longer in pancreatic cancer [18]. Subsequently in a recent retrospective study, Hohla F. et al. found female gender was a protective factor in FOLFIRINOX treatment of unresectable pancreatic cancer [19]. Gender difference in cancer susceptibility and prognosis may be associated with different role of hormones as the promoting action of androgens and protective action of estrogens on pancreatic carcinogenesis $[20,21]$. Besides the ECOG status, gender balance should be taken into consideration for randomize balance in future phase III trials. In patients developed grade 3 or 4 leukopenia or neutropenia, we highly suggest the patient should be encouraged for continuous treatment in case of reversal of the adverse event.

There were limitations in our study. This was a single-center, single-arm, nonrandomized trial. Another limitation of our study was that we did not test the levels of thymidylate synthase (TS), orotate phosphoribosyltransferase (OPRT) and dihydropyrimidine dehydrogenase (DPD), which were considered potentially being associated with the efficacy and safety of S-1 [22]. Due to potential difference between Westerners and Asians in pharmacokinetics and pharmacodynamics of S-1, it is recommended that the plasma concentration, and effectiveness and toxicity related biomarkers (TS and DPD) should be monitored and examined if the similar regimen is applied to Western patients [23]. Emerging evidence showed that metabolic response was associated with greater efficacy and longer survival [24], however we did not perform positron emission tomography (PET) for metabolic response assessment in our protocol. Limited sample size and mixed 5 cases of locally advanced PAC into metastatic PAC were also our limitations. However, this was the first study to discover the promising favorable response of the combination of nab-paclitaxel with S-1 in advanced PAC.

In conclusion, nab-paclitaxel plus S-1 demonstrated a remarkable antitumor activity with good tolerability and manageable toxicity as the first-line treatment in patients with advanced PAC in Chinese population. Given the convenient administration of S-1, we found this regimen was more manageable practically. The significant ORR made us believe this treatment regimen is potentially an effective alternative for those with gemcitabine allergy and poor compliance with nab-paclitaxel and gemcitabine or FOLFIRINOX treatment. Given the promising efficacy and safety of nab-paclitaxel plus S-1, a larger randomized phase III trial is warranted.

\section{MATERIALS AND METHODS}

\section{Patients}

The study protocol was approved by the ethics committee of the Chinese PLA General Hospital (No. S2014-031-01), and all procedures were in accordance with the ethical standards of the responsible committee on human experimentation (institutional and national) and with the Declaration of Helsinki and Good Clinical Practice guidelines. All patients provided written informed consent before entering the study.

Patients eligible for enrollment were: a) adults no less than 18 years of age; b) histologically or cytologically confirmed locally advanced or metastatic PAC; c) ECOG performance status of 0 or 1 with life expectancy no less than 12 weeks; d) having at least one measurable disease by computed tomography (CT) as defined in the RECIST version 1.1 [25]; e) no previous 5-fluorouracil or gemcitabine treatment unless they were used in the adjuvant setting for radiation therapy no less than 6 months and no lingering toxicities were present before enrollment; f) adequate bone marrow (absolute neutrophil count $\geq 1.5 \mu \mathrm{L}$ and platelets $\geq 100,000 \mu \mathrm{L}$ ) and liver functions (bilirubin $\leq 1.5$ times the upper limit of the normal range), and normal renal function.

Patients were excluded from the enrollment if they: a) were endocrine or acinar pancreatic carcinoma; b) had history of other malignancy; c) had uncontrolled brain metastasis or mental illness; d) had uncontrolled concomitant medical illnesses (e.g., active infection, cardiac disease and sever peripheral neuropathy), e) were pregnancy or breast-feeding.

\section{Study design and treatment}

This study was a prospective, single center, single arm, open label phase II clinical trial conducted in PLA General Hospital in China. Nab-paclitaxel 
was administered at $120 \mathrm{mg} / \mathrm{m}^{2}$ in 30 to 40 minute intravenously on day 1 and $8, \mathrm{~S}-1$ was given twice a day orally at a dose according to the body surface area (BSA) $\left(<1.25 \mathrm{~m}^{2}, 80 \mathrm{mg} / \mathrm{d} ; \geq 1.25\right.$ to $<1.5 \mathrm{~m}^{2}, 100 \mathrm{mg} / \mathrm{d} ; \geq$ $1.5 \mathrm{~m}^{2}, 120 \mathrm{mg} / \mathrm{d}$ ) on days 1 through 14 of each 21-day cycle. Given the dosage of nab-paclitaxel was reduced in $41 \%$ patients and the median relative dose intensity of nab-PTX was $81 \%$ in MPACT study, the lower dose of nab-paclitaxel was used with dose intensity at $80 \mathrm{mg} /$ $\mathrm{m}^{2}$ per week in this study. Six cycles of chemotherapy were planned for patients who had a response. The treatment discontinued if patient had disease progression, unacceptable toxicity, or request of stop treatment. In patients with clinical benefit after completion of 6-cycle treatment or treatment discontinued, S-1 monotherapy was allowed to be given as maintenance therapy at investigator's discretion according to patients' desire and ECOG performance status. Patients were followed up every 2 months until death.

Dose interruption or discontinuation was permitted in case of grade 3 to 4 hematologic or grade 3 nonhematologic toxicity, and supportive management was instituted. Dose adjustments of either nab-paclitaxel or S-1 were allowed but no more than twice for each patient, whereas nab-paclitaxel could be adjusted to $100 \mathrm{mg} / \mathrm{m}^{2}$ and $80 \mathrm{mg} / \mathrm{m}^{2}$ subsequently, and $\mathrm{S}-1$ could reduce by $20 \mathrm{mg}$ per day every time if reversal of toxicity to grade 1 or better within 28 days; otherwise, the treatment was terminated.

\section{Assessments}

Clinical and laboratory evaluations, including the change of serum CA19-9, were performed at baseline and every 3 weeks. Adverse events were assessed by the investigators before each cycle according to the National Cancer Institute Common Terminology Criteria for Adverse Events (version 4.0). Tumor responses including $\mathrm{CR}, \mathrm{PR}$, stable disease (SD), or progressive disease (PD) were evaluated on $\mathrm{CT}$ or magnetic resonance imaging (MRI) according to RECIST 1.1 at baseline and every 6 weeks ( \pm 7 days) by the investigators and blinded independent reviewer (X.M.). 18F-fluorodeoxygluscose PET scan was used to confirm CR.

\section{Statistical analysis}

The primary endpoint was ORR, the secondary endpoints were PFS, OS and safety. The ORR was calculated as the number of patients with CR or PR divided by the total number of patients, whereas CR or PR was confirmed on imaging assessment 4 weeks apart per RECIST 1.1 criteria. OS and PFS were calculated from the date of the treatment initiation until the date of death or the date of documentation of disease progression or death in patients without disease progression, whichever occurred first. The censoring date was the last date of available follow-up.
The sample size was determined using a one stage design, with the assumption that an increase of ORR from $8 \%$ (the ORR of gemcitabine alone based on prior studies of first-line treatment in metastatic PAC) to $20 \%$ with a significance level of 0.05 and a power of $80 \%$. Considering a $10 \%$ drop off rate, total 60 patients were required.

Demographic and baseline characteristics, response rates and safety observations were summarized using descriptive statistics. The $\chi 2$ test was performed to compare the ORR between different subgroups. PFS and OS were estimated using Kaplan-Meier method, and the difference in survival between subgroups was assessed by the log-rank test. The statistical significance was defined as a two-sided $\mathrm{P}<0.05$. All statistical analyses were conducted by a statistician (S.Z.) using SAS software (version 9.4; SAS Institute, Cary, North Carolina).

\section{Abbreviations}

BIR, blinded independent review; CA19-9, carbohydrate antigen 19-9; CR, complete response; DCR, disease control rate; DPD, dihydropyrimidine dehydrogenase; ECOG, Eastern Cooperative Oncology Group; ITT, intention-to-treat; OPRT, orotate phosphoribosyl-transferase; ORR, objective response rates; OS, overall survival; PAC, pancreatic adenocarcinoma; PDX, patient-derived xenograft; PET, positron emission tomography; PD, progressive disease; PFS, progression-free survival; PR, partial response; SD, stable disease; TS, thymidylate synthase

\section{Author contributions}

Conception and design: Yan Shi, Quanli Han, Rong Liu, Guanghai Dai

Provision of study materials or patients: Yan Shi, Quanli Han, Huaiyin Shi, Guanghai Dai

Collection and assembly of data: Yan Shi, Huan Yan, Jie Li, Quanli Han, Yao Lv, Huaiyin Shi

Data analysis and interpretation: Yan Shi, Sui Zhang, Quanli Han, Huan Yan, Jie Li, Yao Lv, Rong Liu, Guanghai Dai

Manuscript writing: Yan Shi, Sui Zhang, Huan Yan, Guanghai Dai

Final approval of manuscript: All authors

\section{ACKNOWLEDGMENTS}

The authors thank Dr. Xiaozhou Ma, Muhong Deng, Hongxia Guo for their valuable comments and assistance in this study.

\section{CONFLICTS OF INTEREST}

The authors have declared no conflicts of interest. 


\section{REFERENCES}

1. Ferlay J, Soerjomataram I, Dikshit R, Eser S, Mathers C, Rebelo M, Parkin DM, Forman D, Bray F. Cancer incidence and mortality worldwide: sources, methods and major patterns in GLOBOCAN 2012. Int J Cancer. 2015; 136:E359-86.

2. Chen W, Zheng R, Baade PD, Zhang S, Zeng H, Bray F, Jemal A, Yu XQ, He J. Cancer statistics in China, 2015. CA Cancer J Clin. 2016; 66:115-32.

3. Bond-Smith G, Banga N, Hammond TM, Imber CJ. Pancreatic adenocarcinoma. BMJ. 2012; 344:e2476.

4. Balaban EP, Mangu PB, Khorana AA, Shah MA, Mukherjee $\mathrm{S}$, Crane $\mathrm{CH}$, Javle MM, Eads JR, Allen P, Ko AH, Engebretson A, Herman JM, Strickler JH, et al. Locally Advanced, Unresectable Pancreatic Cancer: American Society of Clinical Oncology Clinical Practice Guideline. J Clin Oncol. 2016; 34:2654-68.

5. Sohal DP, Mangu PB, Khorana AA, Shah MA, Philip PA, O'Reilly EM, Uronis HE, Ramanathan RK, Crane CH, Engebretson A, Ruggiero JT, Copur MS, Lau M, et al. Metastatic Pancreatic Cancer: American Society of Clinical Oncology Clinical Practice Guideline. J Clin Oncol. 2016; 34:2784-96.

6. Burris HA 3rd, Moore MJ, Andersen J, Green MR, Rothenberg ML, Modiano MR, Cripps MC, Portenoy RK, Storniolo AM, Tarassoff P, Nelson R, Dorr FA, Stephens CD, Von Hoff DD. Improvements in survival and clinical benefit with gemcitabine as first-line therapy for patients with advanced pancreas cancer: a randomized trial. J Clin Oncol. 1997; 15:2403-13.

7. Di Marco M, Di Cicilia R, Macchini M, Nobili E, Vecchiarelli S, Brandi G, Biasco G. Metastatic pancreatic cancer: is gemcitabine still the best standard treatment? (Review). Oncol Rep. 2010; 23:1183-92.

8. Conroy T, Desseigne F, Ychou M, Bouché O, Guimbaud R, Bécouarn Y, Adenis A, Raoul JL, Gourgou-Bourgade S, de la Fouchardière C, Bennouna J, Bachet JB, KhemissaAkouz F, et al, and Groupe Tumeurs Digestives of Unicancer, and PRODIGE Intergroup. FOLFIRINOX versus gemcitabine for metastatic pancreatic cancer. N Engl J Med. 2011; 364:1817-25.

9. Moore MJ, Goldstein D, Hamm J, Figer A, Hecht JR, Gallinger S, Au HJ, Murawa P, Walde D, Wolff RA, Campos D, Lim R, Ding K, et al, and National Cancer Institute of Canada Clinical Trials Group. Erlotinib plus gemcitabine compared with gemcitabine alone in patients with advanced pancreatic cancer: a phase III trial of the National Cancer Institute of Canada Clinical Trials Group. J Clin Oncol. 2007; 25:1960-66.

10. Von Hoff DD, Ervin T, Arena FP, Chiorean EG, Infante J, Moore M, Seay T, Tjulandin SA, Ma WW, Saleh MN, Harris M, Reni M, Dowden S, et al. Increased survival in pancreatic cancer with nab-paclitaxel plus gemcitabine. N Engl J Med. 2013; 369:1691-703.
11. Ueno H, Ioka T, Ikeda M, Ohkawa S, Yanagimoto H, Boku N, Fukutomi A, Sugimori K, Baba H, Yamao K, Shimamura T, Sho M, Kitano M, et al. Randomized phase III study of gemcitabine plus S-1, S-1 alone, or gemcitabine alone in patients with locally advanced and metastatic pancreatic cancer in Japan and Taiwan: GEST study. J Clin Oncol. 2013; 31:1640-48.

12. Uesaka K, Boku N, Fukutomi A, Okamura Y, Konishi M, Matsumoto I, Kaneoka Y, Shimizu Y, Nakamori S, Sakamoto H, Morinaga S, Kainuma O, Imai K, et al, and JASPAC 01 Study Group. Adjuvant chemotherapy of S-1 versus gemcitabine for resected pancreatic cancer: a phase 3, open-label, randomised, non-inferiority trial (JASPAC 01). Lancet. 2016; 388:248-57.

13. Suenaga M, Yamada S, Fujii T, Tanaka C, Kanda M, Nakayama G, Sugimoto H, Koike M, Fujiwara M, Kodera Y. S-1 plus nab-paclitaxel is a promising regimen for pancreatic cancer in a preclinical model. J Surg Oncol. 2016; 113:413-19.

14. Li JA, Xu XF, Han X, Fang Y, Shi CY, Jin DY, Lou WH. Nab-Paclitaxel Plus S-1 Shows Increased Antitumor Activity in Patient-Derived Pancreatic Cancer Xenograft Mouse Models. Pancreas. 2016; 45:425-33.

15. Nakayama N, Ishido K, Chin K, Nishimura K, Azuma M, Matsusaka S, Inokuchi Y, Tanabe S, Kumekawa Y, Koizumi W. A phase I study of S-1 in combination with nab-paclitaxel in patients with unresectable or recurrent gastric cancer. Gastric Cancer. 2017; 20:350-57.

16. Tsurutani J, Kuroi K, Iwasa T, Miyazaki M, Nishina S, Makimura C, Tanizaki J, Okamoto K, Yamashita T, Aruga T, Shigekawa T, Komoike Y, Saeki T, Nakagawa K. Phase I study of weekly nab-paclitaxel combined with S-1 in patients with human epidermal growth factor receptor type 2-negative metastatic breast cancer. Cancer Sci. 2015; 106:734-39.

17. Bachet JB, Hammel P, Desramé J, Meurisse A, Chibaudel B, André T, Debourdeau P, Dauba J, Lecomte T, Seitz JF, Tournigand C, Aparicio T, Meyer VG, et al. Nabpaclitaxel plus either gemcitabine or simplified leucovorin and fluorouracil as first-line therapy for metastatic pancreatic adenocarcinoma (AFUGEM GERCOR): a noncomparative, multicentre, open-label, randomised phase 2 trial. Lancet Gastroenterol Hepatol. 2017; 2:337-46.

18. Micheli A, Mariotto A, Giorgi Rossi A, Gatta G, Muti P, and EUROCARE Working Group. The prognostic role of gender in survival of adult cancer patients. Eur J Cancer. 1998; 34:2271-78.

19. Hohla F, Hopfinger G, Romeder F, Rinnerthaler G, Bezan A, Stättner S, Hauser-Kronberger C, Ulmer H, Greil R. Female gender may predict response to FOLFIRINOX in patients with unresectable pancreatic cancer: a single institution retrospective review. Int J Oncol. 2014; 44:319-26.

20. Sumi C, Longnecker DS, Roebuck BD, Brinck-Johnsen T. Inhibitory effects of estrogen and castration on the early 
stage of pancreatic carcinogenesis in Fischer rats treated with azaserine. Cancer Res. 1989; 49:2332-36.

21. Dorak MT, Karpuzoglu E. Gender differences in cancer susceptibility: an inadequately addressed issue. Front Genet. 2012; 3:268.

22. Chhetri P, Giri A, Shakya S, Shakya S, Sapkota B, Pramod KC. Current Development of Anti-Cancer Drug S-1. J Clin Diagn Res. 2016; 10:XE01-05.

23. Chuah B, Goh BC, Lee SC, Soong R, Lau F, Mulay M, Dinolfo M, Lim SE, Soo R, Furuie T, Saito K, Zergebel C, Rosen LS. Comparison of the pharmacokinetics and pharmacodynamics of S-1 between Caucasian and East Asian patients. Cancer Sci. 2011; 102:478-83.
24. Ramanathan RK, Goldstein D, Korn RL, Arena F, Moore M, Siena S, Teixeira L, Tabernero J, Van Laethem JL, Liu H, McGovern D, Lu B, Von Hoff DD. Positron emission tomography response evaluation from a randomized phase III trial of weekly nab-paclitaxel plus gemcitabine versus gemcitabine alone for patients with metastatic adenocarcinoma of the pancreas. Ann Oncol. 2016; 27:648-53.

25. Eisenhauer EA, Therasse P, Bogaerts J, Schwartz LH, Sargent D, Ford R, Dancey J, Arbuck S, Gwyther S, Mooney M, Rubinstein L, Shankar L, Dodd L, et al. New response evaluation criteria in solid tumours: revised RECIST guideline (version 1.1). Eur J Cancer. 2009; 45:228-47. 